九州大学学術情報リポジトリ

Kyushu University Institutional Repository

\title{
Contribution of Catalytic Performance of Ce0_2 in Nonthermal Plasma Chemical Reaction
}

Egawa, Yusuke

Interdisciplinary Graduate School of Engineering, Kyushu University

Hamada, Shoma

Interdisciplinary Graduate School of Engineering, Kyushu University

Einaga, Hisahiro

Faculty of Engineering Sciences, Kyushu University

https://doi.org/10.5109/1957498

出版情報 : Evergreen. 5 (3)，pp.34-37，2018-09. 九州大学グリーンアジア国際リーダー教育センター バージョン：

権利関係 : 


\title{
Contribution of Catalytic Performance of $\mathrm{CeO}_{2}$ in Nonthermal Plasma Chemical Reaction
}

\author{
Yusuke Egawa*, Shoma Hamada, Hisahiro Einaga \\ Interdisciplinary Graduate School of Engineering, Kyushu University, Japan \\ 6-1 Kasuga-kouen, Kasuga, Fukuoka, 816-8580, Japan \\ E-mail: yusuke@aees.kyushu-u.ac.jp
}

(Received November 15, 2017; accepted September 20, 2018).

\begin{abstract}
Benzene is a harmful material that must be to be removed from flue gases. In this study, the performance of a surface discharge plasma-catalysis combined reactor for benzene decomposition was studied. Benzene conversion and $\mathrm{CO}_{2}$ selectivity increased upon loading a $\mathrm{CeO}_{2}$ catalyst onto the plasma reactor. The conversion and selectivity depended on the surface area of the $\mathrm{CeO}_{2}$. FTIR studies revealed that byproduct organic compounds are formed on the $\mathrm{CeO}_{2}$, confirming that benzene oxidation occurs on the $\mathrm{CeO}_{2}$ catalysts.
\end{abstract}

Keywords: benzene conversion, $\mathrm{CeO}_{2}$, nonthermal plasma, plasma catalysis

\section{Introduction}

Air pollution caused by photochemical oxidants and suspended particulate matter (SPM) is a serious environmental problem. Recently, regulations pertaining to the emission of volatile organic compounds (VOCs) have been strengthened because they are known to be causative agents of the photochemical oxidants and SPM. VOC abatement processes such as adsorption, thermal incineration, and catalytic oxidation are widely used for treatment of the exhaust gases from industrial processes. However, these conventional processes require hightemperature pressure swing processes. These processes can be only applied to large-scale stationary sources. Therefore, emission control technologies that can remove low-concentration VOCs at low temperature are required.

The combination of nonthermal plasma (NTP) and catalysis is an effective way to decompose lowconcentration VOCs at low temperature ${ }^{1-3)}$ NTP processes present advantages over conventional VOC abatement processes in that low-cost and small-sized reactors can be easily constructed and their operation is simpler than that of conventional processes. Thus, NTP processes can be used in small-scale factories.

In NTP reactions, highly energized electrons and active oxygen species are the dominant species that contribute to VOC decomposition. However, harmful byproducts such as $\mathrm{CO}$ are generally formed with high selectivity during VOC decomposition using NTP reactors. In addition, energy efficiency must be improved if NTP processes are to be put to practical use. To overcome these problems, NTP reactions are combined with catalytic reactions because catalytic materials can utilize the active species formed in the NTP reaction. Precedent studies have shown that the loading of manganese oxide ${ }^{4}$, titanium oxide ${ }^{5)}$ or alumina in NTP reactors improves the efficiency of VOC decomposition.

In this study, gas-phase benzene decomposition was carried out using a surface discharge reactor combined with $\mathrm{CeO}_{2}$ catalysis. Benzene is a ubiquitous material and is one of the most common VOCs that must be removed from flue gases owing to its carcinogenicity. The effect of catalyst loading on the efficiency of benzene decomposition and $\mathrm{CO}_{\mathrm{x}}$ formation was investigated.

\section{Experimental}

\subsection{Materials}

Three types of $\mathrm{CeO}_{2}$ catalyst were supplied by the Catalysis Society of Japan (JRC-CEO-1, CEO-2, CEO-3). The catalysts were used as received. The detailed characteristics of each catalyst are shown in Table 1.

\subsection{Characteristics of plasma reactors and experimental systems}

Figure 1 shows a schematic of the surface discharge reactor used in this study. The reactor was composed of a branched glass tube (effective length: $10 \mathrm{~cm}$ ) in which a copper wire coil wound around a glass rod $(6 \mathrm{~mm})$ was used as an internal electrode. The glass tube was wrapped with aluminum foil as a counter electrode. The surface discharge reactor was connected to a fixed bed flow reaction system as shown below. A catalyst sample (0.20 g) was set in the surface discharge reactor. The reactor was energized at $60 \mathrm{~Hz}$ with an input power of up to $3 \mathrm{~W}$. 


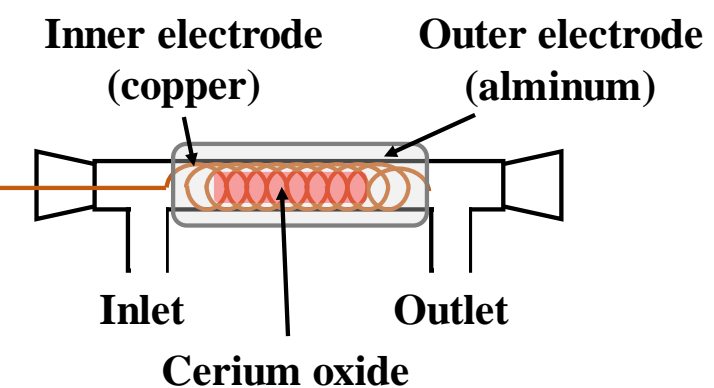

Fig. 1: Schematic of surface discharge reactor

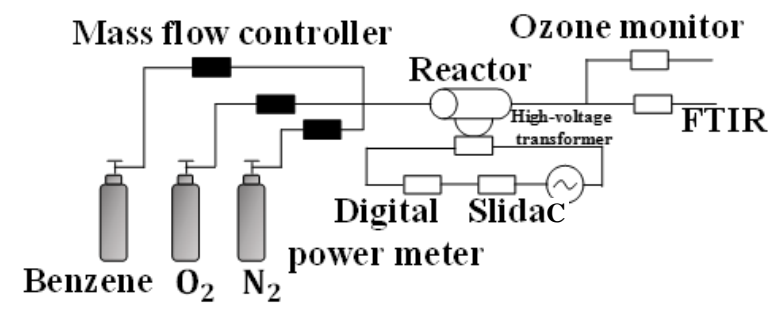

Fig. 2: The schematic of the reaction system.

Table 1 Textual properties of $\mathrm{CeO}_{2}$

\begin{tabular}{cccc}
\hline & CEO-1 & CEO-2 & CEO-3 \\
\hline crystallite size $(\mathrm{nm})$ & 7.4 & 8.7 & 11.0 \\
surface area $\left(\mathrm{m}^{2} / \mathrm{g}\right)$ & 156.9 & 123.1 & 81.4 \\
pore diameter $(\mathrm{nm})$ & 2.82 & 7.08 & 11.6 \\
pore volume $(\mathrm{ml} / \mathrm{g})$ & 0.11 & 0.23 & 0.24 \\
D50 $(\mu \mathrm{m})$ & 21.31 & 4.36 & 4.37 \\
Median diameter & & & \\
\hline
\end{tabular}

\subsection{Benzene decomposition with surface discharge} reactor

Figure 2 shows a schematic of the reaction system used in this study. Analysis of the reaction gas was performed with an FTIR spectrometer (Perkin Elmer Spectrum 100) equipped with a gas cell (optical length: $2.4 \mathrm{~m}$ ). The input power was measured by a digital power meter (Yokogawa WT310).

The reaction gas (benzene $200 \mathrm{ppm}, \mathrm{O}_{2} 20 \%, \mathrm{~N}_{2}$ balance) was prepared from benzene in $\mathrm{N}_{2}, \mathrm{~N}_{2}$, and $\mathrm{O}_{2}$ from cylinders. The gas was fed to the reactor at a flow rate of $100 \mathrm{~mL} / \mathrm{min}$. After adsorption-desorption equilibrium was achieved for benzene, the input power was gradually increased to $3 \mathrm{~W}$, and the concentrations of benzene and COx were measured using the FTIR spectrometer.

From the following calculation formulas (1) and (2), benzene conversion and $\mathrm{CO}_{2}$ selectivity were calculated.

$$
\frac{\left[\mathrm{C}_{6} \mathrm{H}_{6}\right]_{0}-\left[\mathrm{C}_{6} \mathrm{H}_{6}\right]}{\left[\mathrm{C}_{6} \mathrm{H}_{6}\right]_{0}} \times 100
$$

Here, $\left[\mathrm{C}_{6} \mathrm{H}_{6}\right]_{0}$ and $\left[\mathrm{C}_{6} \mathrm{H}_{6}\right]$ are the benzene concentrations in the inlet and outlet gases.

$$
\frac{\left[\mathrm{CO}_{2}\right]}{6\left\{\left[\mathrm{C}_{6} \mathrm{H}_{6}\right]_{0}-\left[\mathrm{C}_{6} \mathrm{H}_{6}\right]\right\}} \times 100
$$

$\left[\mathrm{CO}_{2}\right]$ : $\mathrm{CO}_{2}$ concentration during steady state.

\subsection{V-Q Lissajous figure}

In this study, a V-Q Lissajous figure was used as a discharge measurement of the reactor. Figure 3 shows the measurement system for the $\mathrm{V}-\mathrm{Q}$ Lissajous figure.

In a V-Q Lissajous figure, the horizontal axis is the voltage of the reactor and the vertical axis is the electric charge that flows into the reactor. In this study, a 1-nF capacitor was connected to the reactor in series. Its potential difference was measured and the electric charge was calculated.

\section{Results and discussion}

\subsection{Energy consumption in the reactor.}

The input power applied to the surface discharge reactor was $3 \mathrm{~W}$. The energy density in the reactor used for plasma production was calculated from the V-Q Lissajous figure shown in Fig. 4. The area of the graphic surrounded by the V-Q Lissajous figure corresponds to the energy input to the plasma per voltage cycle. From this result, the input energy density was $926.8 \mathrm{~J} / \mathrm{L}$ at a input power of $1.54 \mathrm{~W}$. The gas flow rate was $100 \mathrm{~mL} / \mathrm{min}$.

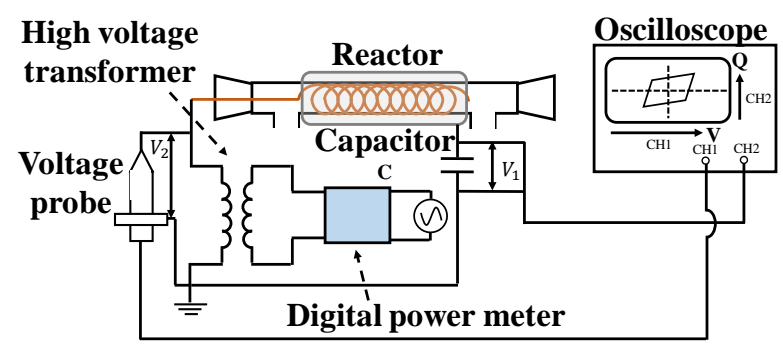

Fig. 3: the measurement system of V-Q Lissajous figure.

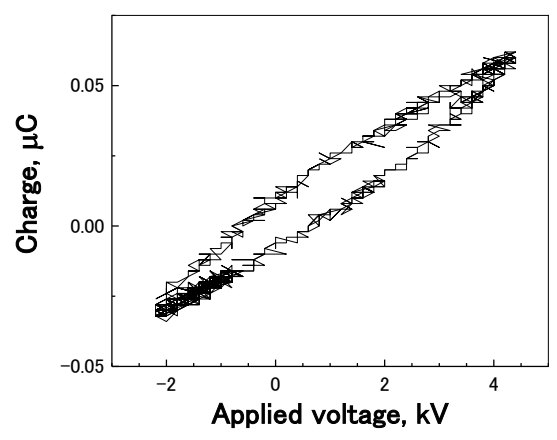

Fig. 4: Q-V Lissagous figure. 


\subsection{Benzene decomposition with surface discharge reactor with $\mathrm{CeO}_{2}$}

Figure 5 shows the change in the benzene concentration in the gas stream effluent from the surface discharge reactor equipped with the $\mathrm{CeO}_{2}$ catalyst. Without plasma ignition, benzene is adsorbed on the catalyst and the benzene concentration increases with time on stream. The time required for adsorption-desorption equilibrium for benzene between the catalyst surface and the gas phase was changed from 10 to 90 min depending on the kind of $\mathrm{CeO}_{2}$ catalyst employed. The difference in benzene adsorption behavior is ascribed to the difference in the surface area and the average pore diameter of the $\mathrm{CeO}_{2}$ catalyst, which are the factors controlling benzene adsorption capacity. $\mathrm{CeO}_{2}$ (JRC-CEO-1) has the largest surface area and the smallest average pore diameter. Therefore, the sample required the longest time for adsorption-desorption equilibrium to be achieved. These findings show that JRC-CEO-1 has the largest capacity for benzene adsorption, whereas JRC-CEO-3 has the smallest capacity.

When an input power of $3 \mathrm{~W}$ is applied to the electrode, plasma is ignited inside the reactor and the amount of benzene in the gas stream drastically decreases. Table 2 shows the results for benzene decomposition at steady state. In the case of the plasma reaction without $\mathrm{CeO}_{2}$, benzene conversion is $38.9 \%$. When $\mathrm{CeO}_{2}$ is placed inside the reactor, benzene conversion increases. The benzene conversions are $86.9 \%, 76.1 \%$, and $47.6 \%$ for JRC-CEO1, JRC-CEO-2, and JRC-CEO-3, respectively. Thus, the benzene conversion depends on the adsorption capacity of the $\mathrm{CeO}_{2}$ catalyst. JRC-CEO-1 exhibits the highest activity for benzene oxidation under plasma irradiation.

Figure 6 shows the changes in the amount of $\mathrm{CO}_{2}$ formed with time on stream. When an input power of $3 \mathrm{~W}$ is applied to the electrode, the amount of $\mathrm{CO}_{2}$ dramatically increases. In the plasma chemical reaction without a $\mathrm{CeO}_{2}$ catalyst, the $\mathrm{CO}_{2}$ selectivity is $50.9 \%$. When JRC-CEO-1, JRC-CEO-2, and JRC-CEO-3 are used in the reaction, the $\mathrm{CO}_{2}$ selectivities increase to $67.4 \%, 69.2 \%$, and $59.8 \%$ respectively. Thus, loading the $\mathrm{CeO}_{2}$ catalyst onto the surface discharge reactor is effective for promoting benzene oxidation and $\mathrm{CO}_{2}$ formation in the plasma chemical reaction.

It should be noted that $\mathrm{CO}_{2}$ selectivity gradually decreases owing to the formation of intermediate products during the plasma ignition. Formic acid is observed in the gas stream effluent from the reactor. This is a typical intermediate compound in benzene oxidation with plasma-catalytic reaction system. Formic acids are easily adsorbed on metal oxide surfaces to form strongly bound surface formates, which prevent benzene oxidation on the metal oxide surface. Therefore, the decrease in benzene conversion with time on stream was ascribed to the buildup of intermediates on the catalyst surface.

It has been reported that $\mathrm{CeO}_{2}$ is active for $\mathrm{O}_{3}$ decomposition and $\mathrm{CO}$ oxidation by $\mathrm{O}_{3}$ at room temperature. ${ }^{6}$ ESR and FTIR studies have revealed that $\mathrm{O}_{3}$ is adsorbed on $\mathrm{CeO}_{2}$ to form surface ozonide, $\mathrm{O}_{3}{ }^{-}$, and that nondissociative $\mathrm{O}_{3}$ decomposition takes place on $\mathrm{CeO}_{2}$. This is in marked contrast with the mechanism for $\mathrm{O}_{3}$ decomposition on transition metal oxides such as $\mathrm{MnOx}$. It has been concluded that atomic oxygen species $\left(\mathrm{O}^{*}\right)$ contribute to the oxidation of benzene and peroxide $\left(\mathrm{O}_{2}{ }^{*}\right)$ is the spectator.

Table 2 Benzene conversion rate $\mathrm{CO}_{2}$ selectivity

\begin{tabular}{|c|c|c|c|c|}
\hline & $\begin{array}{c}\text { without } \\
\mathrm{CeO}_{2}\end{array}$ & $\mathrm{CEO}-1$ & $\mathrm{CEO}-2$ & $\mathrm{CEO}-3$ \\
\hline $\begin{array}{c}\text { conversion } \\
\text { rate (\%) }\end{array}$ & 38.9 & 86.9 & 76.1 & 47.6 \\
\hline $\begin{array}{c}\mathrm{CO}_{2} \\
\text { selectivity (\%) }\end{array}$ & 50.9 & 67.4 & 69.2 & 59.8 \\
\hline
\end{tabular}

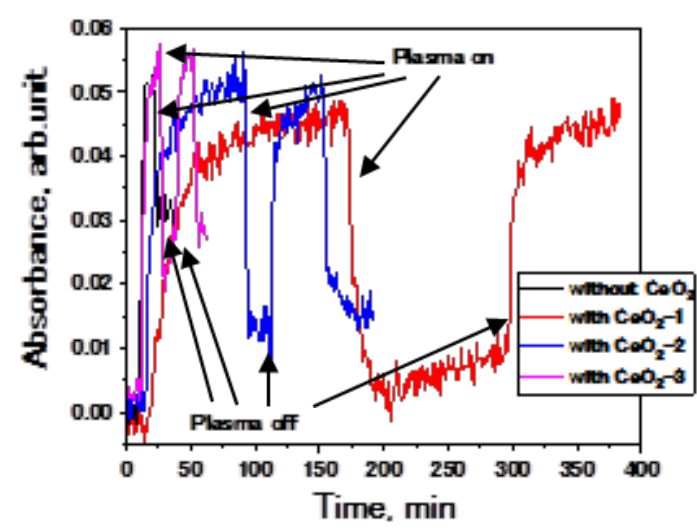

Fig. 5: Amount of benzene variation with time.

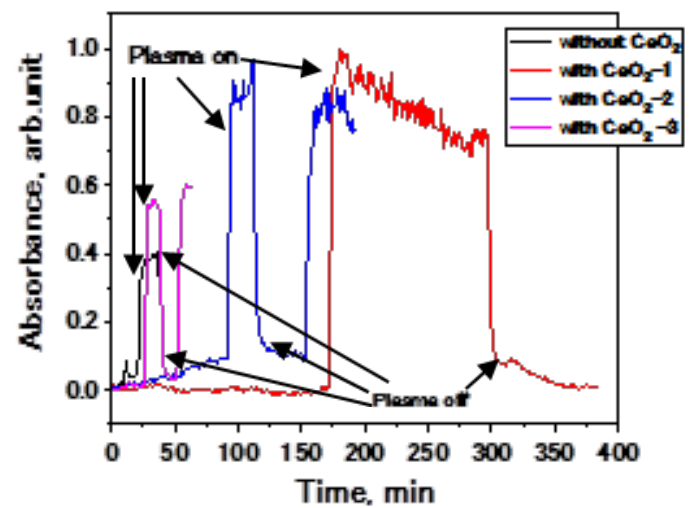

Fig. 6: . $\mathrm{CO}_{2}$ variation with time.

$$
\mathrm{O}\left({ }^{3} \mathrm{P}\right)+\mathrm{O}_{2}+\mathrm{M} \rightarrow \mathrm{O}_{3}
$$




\subsection{Characterization of the $\mathrm{CeO}_{2}$ used in the surface discharge reaction}

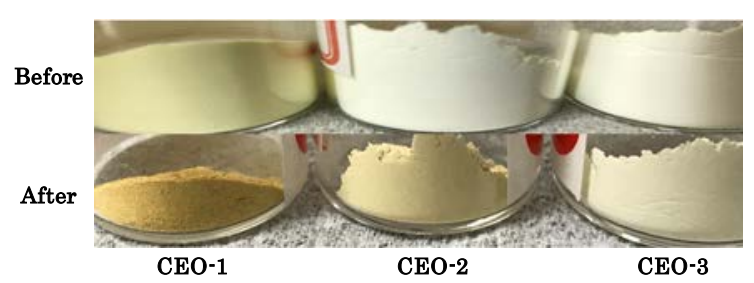

Fig. 7: color change of $\mathrm{CeO}_{2}$ after plasma irradiation.

During the benzene oxidation, the color of the $\mathrm{CeO}_{2}$ changes to brown, as shown in Fig. 7. We at first investigated whether structural changes occur during the plasma irradiation. Raman studies for the used $\mathrm{CeO}_{2}$ catalysts were performed because Raman spectra provide information about their crystal structures. Figure 8 shows the Raman spectra of $\mathrm{CeO}_{2}$ samples used for benzene decomposition. Characteristic bands assignable to the $F_{2 g}$ vibration mode are observed at $532 \mathrm{~cm}^{-1}$. No difference is observed for the $\mathrm{CeO}_{2}$ before and after plasma irradiation, indicating that the $\mathrm{CeO}_{2}$ structure does not change during the reaction.

Subsequently, we performed FTIR analysis of the used $\mathrm{CeO}_{2}$ samples to identify the intermediate species formed on the catalyst surface. Figure 9 shows the FTIR spectra of the $\mathrm{CeO}_{2}$ (JRC-CEO-2) sample before and after benzene decomposition. For the $\mathrm{CeO}_{2}$ sample before reaction, the bands due to water adsorbed on the $\mathrm{CeO}_{2}$ are observed. After the reaction, new bands appear in the ranges $860-1192 \mathrm{~cm}^{-1}$ and $1256-1506 \mathrm{~cm}^{-1}$. These bands are ascribed to the formation and build-up of organic byproducts on the $\mathrm{CeO}_{2}$ surface, including strongly bound surface formates. Thus, benzene oxidation proceeds on the $\mathrm{CeO}_{2}$ surface, and the color change of $\mathrm{CeO}_{2}$ is caused by the formation of byproduct compounds. Figure 9 also shows the band at $1400 \mathrm{~cm}^{-1}$ due to the formation of $\mathrm{NO}_{3}{ }^{-}$ species adsorbed on $\mathrm{CeO}_{2}$, which are derived from the oxidation of $\mathrm{NO}$ and $\mathrm{NO}_{2}$ formed in the plasma irradiation.

\section{Conclusions}

In this study, we studied the decomposition of benzene as a model VOC using a surface discharge-catalyst combined reactor. The effect of $\mathrm{CeO}_{2}$ loading on benzene decomposition was investigated in detail. The benzene conversion and $\mathrm{CO}_{2}$ selectivity were improved by the combination of low-temperature plasma and catalyst. $\mathrm{CeO}_{2}$ with the highest surface area and the smallest pore size exhibited the highest activity for benzene decomposition. This finding indicates that the capacity for benzene adsorption is the most important factor controlling catalytic performance.

In terms of future work, we intend to put our VOC decomposition reactor to practical use. Therefore, we will optimize the nonthermal plasma reactor and catalytic materials to improve the benzene oxidation efficiency and
$\mathrm{CO}_{2}$ formation selectivity on the basis of the results in this study.

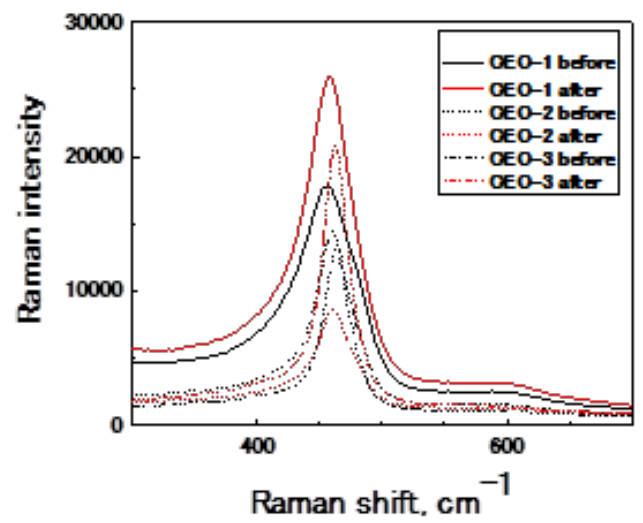

Fig. 8: Raman spectra

\section{References}

1) A Mizuno, J. S. Clements and R. H. Davis, IEEE Trans Ind. Applicat., 22, 516 (1986).

2) Erik C. Neyts, "Plasma-Surface Interactions in Plasma Catalysis”, Plasma Chem Plasma Process, 36, 185-212 (2016).

3) J. Christopher Whitehea, "Plasma catalysis: A solution for environmental problems", Pure Appl. Chem., 82(6), 1329-1336 (2010).

4) Hisahiro Einaga, Takashi Ibusuki, and Shigeru Futamura, "Performance Evaluation of a Hybrid System Comprising Silent Discharge Plasma and Manganese Oxide Catalysts for Benzene Decomposition”, IEEE Trans. Ind. Applicat., 37(5) (2001).

5) Taizo Sano, Nobuaki Negishi, Emiko Sakai, and Sadao Matsuzawa, "Contributions of photocatalytic/catalytic activities of $\mathrm{TiO}_{2}$ and $\gamma$ $\mathrm{Al}_{2} \mathrm{O}_{3}$ in nonthermal plasma on oxidation of acetaldehyde and CO”, Journal of Molecular Catalysis A: Chemical, 245, 235-241 (2006).

6) K. M. Bulanin, J. C. Lavelly, J. Lamottee, L. Mariety, N. M. Tsyganeko, and A. A. Tsyganeko, "Infared Study of Ozone Adsorption on $\mathrm{CeO}_{2}$ ”, J. Phys. Chem. B, 102, 6809-6816 (1998). 